\title{
Molybdenum isotope systematics at the Tonga subduction zone: The role of the metasomatized forearc mantle
}

QASID AHMAD ${ }^{1}$, MARTIN WILLE ${ }^{1}$, STEPHAN KÖNIG ${ }^{2}$, CAROLINA ROSCA ${ }^{2}$, ANGELA HENSEL ${ }^{1}$, DR. THOMAS PETTKE $^{1}$ AND JÖRG HERMANN ${ }^{1}$

${ }^{1}$ University of Bern

${ }^{2}$ University of Tuebingen

Presenting Author: qasid.ahmad@hotmail.de

Molybdenum isotopes have emerged as novel tracers of metal recycling in subduction zones. Open questions remain as to what extent different subducted lithologies, such as oceanic crust and marine sediments, contribute to the Mo isotope signature of arc magmas and hence exert different controls on the terrestrial Mo cycle. To address this, we investigate the Mo isotope signature of input to output at the Tonga subduction zone: basalts and basaltic andesites from different Tongan islands together with pelagic sediments and altered oceanic crust (AOC) samples at DSDP site $595 / 596$ on the subducting Pacific plate. These are complemented by Mo isotope analyses of exhumed subducted sediments and AOC from the Western Alps and Alpine Corsica, which allow to study the fate of Mo with progressive subduction to eclogite facies conditions.

Manganese oxides control Mo concentration and Mo isotope signature in studied pelagic sediments. Their subducted equivalents, pelagic Mn-rich metapelites, display extremely low Mo content and low $\delta^{98 / 95} \mathrm{Mo}$ indicating prominent loss of isotopically heavy Mo already in the forearc. Also, Mo signatures in mafic eclogites are within the range of AOC, yet extending towards lower $\delta^{98 / 95} \mathrm{Mo}$. This is likely due to isotope fractionation during fluid-related Mo mobilization and incorporation of light Mo into residual rutile. Our data thus document prominent loss of isotopically heavy Mo upon early subduction metamorphism. Moreover, when prograde rutile crystallizes, it fixes the largest fraction of Mo in subducting rocks. Consequently, it is very unlikely that slab dehydration processes at subarc depths can account for the observed positive covariations of $\mathrm{Mo} / \mathrm{Ce}$ and $\delta^{98 / 95} \mathrm{Mo}$ with fluid indices, such as $\mathrm{Pb} / \mathrm{Ce}$ and $\mathrm{Ba} / \mathrm{Th}$, in Tongan arc lavas. We suggest that Mo systematics in Tongan arc lavas are the result of fluid-induced Mo mobilization and forearc mantle serpentinization during early stages of subduction. Subsequent mechanical transport and devolatiziation of this metasomatized forearc mantle material at subarc regions is a plausible alternative recycling process. This is supported by positive covariations of $\mathrm{Mo} / \mathrm{Ce}$ and $\delta^{98 / 95} \mathrm{Mo}$ with other fluid mobile elements that are commonly enriched in the metasomatized forearc mantle, such as $\mathrm{As}, \mathrm{Sb}$ and $\mathrm{Cs}$. 